\title{
Sending patients electronic reminders on the need for urgent treatment to prevent life-threatening illnesses: Some lessons to be learned and a cautionary reminder
}

\author{
D J McQuoid-Mason, BComm, LLB, LLM, PhD \\ Centre for Socio-Legal Studies, University of KwaZulu-Natal, Durban, South Africa
}

Corresponding author: D J McQuoid-Mason (mcquoidm@ukzn.ac.za)

\begin{abstract}
A patient's widow recently successfully sued a doctor who had not followed up on unanswered SMS (text) messages sent to her husband warning him that he needed urgent treatment for a life-threatening form of malaria. The messages had gone to her late husband's previous cellphone number and were never received by him. The doctor raised several false defences and attempted to defend himself without being represented by a lawyer. This article highlights a number of important lessons about the dangers of relying exclusively on electronic messaging, raising spurious defences, and resorting to self-representation in serious malpractice cases. It also makes some suggestions on what should be done to avoid such dangers.
\end{abstract}

S Afr Med J 2019;109(11):845-847. https://doi.org/10.7196/SAMJ.2019.v109i11.14113

It was recently reported that a patient had died because his doctor had sent SMS (text) messages warning him about a cerebral malaria diagnosis to the wrong cellphone number, with the result that he was not treated in time. The patient's widow successfully sued the doctor, who conducted his own defence. The doctor was found to be $100 \%$ at fault by the North Gauteng High Court, and the court record was sent to the Health Professions Council of South Africa (HPCSA) for disciplinary action. ${ }^{[1]}$ The case raises the important issue of the lengths to which doctors must go to ensure that patients receive electronic reminders sent to them regarding urgent need for followup treatment. In addition, it raises some self-evident ethical issues regarding communication with clients and when dealing with the court. Finally, the case illustrates the dangers of relying on spurious defences and self-representation in serious cases such as allegations of culpable homicide arising from medical malpractice.

\section{SMS messaging to patients}

In the above case, the doctor claimed that he had sent his longstanding patient several SMS messages informing him that test results indicated that he had cerebral malaria, which could be fatal, and that he should seek treatment urgently. However, the messages were sent to the patient's previous cellphone number and were never received by him. When the doctor received no response from his patient, he took no further action to ascertain whether the cellphone number he was using was the correct one. He claimed that he had tried to follow up the SMSs with phone calls, but this was proved to be false, because such calls would immediately have alerted the doctor to the fact that he was using the wrong number. The doctor also failed to check the patient's file, in which both the patient's wife's and his brother's contact numbers were recorded; either of them could have warned the patient. ${ }^{[1]}$

Such an omission by the doctor was clearly negligence, as he owed his patient a duty of care to ensure that he received the information about the deadly disease he had contracted. The courts have held that failure by a doctor to provide the necessary follow-up information and treatment for a patient is an actionable omission. ${ }^{[2]}$ In the present case, a reasonably competent medical practitioner would have taken urgent steps to ensure that his patient received the information necessary for the treatment of a life-threatening disease, e.g. by contacting the patient's spouse or brother, whose details were in the patient's file. ${ }^{[1]}$

Lessons learned. If an SMS is not delivered, this is usually recorded on the cellphone. However, if 'non-delivery' is not recorded on the cellphone, and a doctor has not received a response from the patient, he or she should follow up with a phone call. If the patient does not answer the phone call, the doctor should check the patient's file to see if there are alternative contact details for the patient, or contact details for the patient's spouse, partner or next of kin, who can be contacted to warn the patient of the urgent need for treatment. It is not enough for a doctor to assume that an unanswered SMS message was received by the patient. It is recommended that in all instances where electronic messaging is used, doctors should make sure that the message has been received by asking their support staff to call the patient to remind them of the need for follow-up treatment.

\section{Whats App messaging to patients}

The doctor in this case also claimed that he had sent his patient a WhatsApp message. However, expert evidence from the service provider was that a WhatsApp message cannot be sent unless the number is on the sender's contact list. In any event, if the doctor had attempted to send a WhatsApp message, he would have seen that there was no blue tick next to it to indicate that the patient had received the message. As a result, the court found that the doctor's allegation that he had used WhatsApp was false. ${ }^{[1]}$

Lessons learned. Doctors using WhatsApp messages to remind patients about the need for appointments must ensure that their patient's cellphone number is on their contact list. They must also ensure that if they do send a WhatsApp message, the message has a blue tick next to it to indicate that it has been delivered. When WhatsApp is used it is recommended that, as in the case of SMS messages, doctors should arrange for their support staff to call their patients to remind them about their follow-up appointments. 


\section{Ethical issues regarding communications with patients and with the court}

The doctor's failure to communicate with his patient and the manner in which he communicated with the court are obvious breaches of his ethical duties. The HPCSA's ethical rules of conduct for practitioners ${ }^{[3]}$ require doctors, inter alia: $(i)$ to act in the best interests of their patients; (ii) to maintain the highest standards of personal conduct and integrity; (iii) to provide adequate information about the patient's diagnosis, treatment options and alternatives; and (iv) to keep their professional knowledge and skills up to date (rule 27A).

It is clear that the doctor in this case did not act in the best interests of his patient by not communicating with him effectively. This failure to communicate deprived the patient of life-saving information about his diagnosis, treatment options and alternatives. The doctor's misrepresentations and lies to the court were in direct violation of his ethical duty to maintain the highest standards of personal conduct and integrity. Also, the doctor's alleged prescription of an ineffective, outdated drug ${ }^{[1]}$ indicated that he was not keeping his professional knowledge and skills up to date.

In addition to the HPCSA's ethical and professional rules, the biomedical ethical principles of patient autonomy, non-maleficence, beneficence and justice ${ }^{[4]}$ also indicate unethical conduct. The patient's autonomy was breached when he was not informed of his diagnosis so that he could undergo live-saving treatment for the particular strain of malaria. The doctor violated the principles of non-maleficence and beneficence by causing harm to the patient, and not acting to the benefit of the patient, by his failure to communicate with him. Finally, it was manifestly unjust for the doctor not to ensure that his communications reached his patient in time to enable the patient to receive life-saving treatment.

Lessons learned. When doctors violate the ethical and professional rules of the HPCSA, and the general ethical principles that may indicate unprofessional conduct, regarding the manner in which they have communicated, or attempted to communicate, with their patients, the court may refer the court record to the HPCSA for disciplinary action. In the case under consideration, the doctor's conduct was especially egregious because of the manner in which he communicated untruths to the court. If the doctor had made these false statements under oath, he could have been criminally prosecuted for perjury. ${ }^{[5]}$

\section{The dangers of raising spurious defences}

The doctor sought to raise a number of spurious defences. In addition to the false allegations that he had tried to call the patient's cellphone number and sent the patient a WhatsApp message, the doctor claimed that his cellphone had been stolen, and as a result he did not realise that the number he had for the patient was wrong. Furthermore, he said that when he could not contact his patient he had immediately faxed a prescription for Halfan, a cerebral malaria drug, to a pharmacy for collection by the patient. ${ }^{[1]}$

All these defences, however, were rejected by the court. The service provider gave evidence that it had no record of the doctor's cellphone being stolen, and expert evidence indicated that even if the doctor had prescribed Halfan, it was an outdated drug and not suitable for the falciparum malaria that had caused the patient's death. ${ }^{[1]}$

The courts have taken a hard line against doctors who rely on spurious defences in cases of medical malpractice and professional negligence. They have awarded adverse costs against doctors who waste the court's time by raising such defences, ${ }^{[6]}$ and when a doctor or a public health official loses a case, they will not only have to pay their own legal costs, but also the attorney and client costs of the other side. ${ }^{[7]}$

Lessons learned. If spurious defences are raised, they will soon be revealed to the court through expert evidence from the plaintiff's witnesses or in cross-examination by the plaintiff's lawyers. In the case of alleged stolen cellphones, it is most unlikely that the theft would not be reported to the person's cellphone provider. If there is no record of such a report, the allegation is likely to be rejected by the court. Likewise, if claims to have faxed prescriptions to pharmacies are made, doctors should make sure that the drug concerned is fit for purpose. A doctor is expected to 'keep his or her professional knowledge and skills up to date. ${ }^{[8]}$ While (in the wording of the Appeal Court) general practitioners are not expected to exercise the same degree of skill and care as specialists, ${ }^{[9]}$ in the case of drug prescriptions they should at least keep up to date regarding the efficacy of the drugs they prescribe. The court in this case regarded the doctor's failure to inform his patient of the danger as negligent and unprofessional conduct and referred the case to the HPCSA. ${ }^{[1]}$ It is likely that the spurious defences raised by the doctor may have contributed to the court's decision in this matter.

\section{Self-representation in serious cases}

The doctor attempted to conduct his own defence in this matter. However, in cases involving death or serious bodily injury arising from medical malpractice or professional negligence, it is most unwise for doctors to try to conduct their own defence - particularly when, if they are unsuccessful, the court record will be sent to the HPCSA for possible disciplinary action. ${ }^{[1]}$ Not only may such doctors be found guilty of unprofessional conduct by the court, but if they have raised spurious defences they will subjected to the penalties mentioned above. ${ }^{[3]}$

Lessons learned. It is dangerous for doctors faced with serious allegations of medical malpractice or professional negligence to attempt to defend themselves, because of the criminal or civil consequences that may result. They may also be exposed to disciplinary action by the HPCSA. ${ }^{[1]}$ Doctors in this situation are well advised to consult their professional indemnity company to secure a lawyer for them if they are insured, or to seek the services of a lawyer if they are not. Lawyers will counsel them on the best course of action. As officers of the court, it would be unethical for lawyers to mislead the court by knowingly eliciting false or untrue evidence from their clients during a hearing. ${ }^{[10]}$ Lawyers are also aware of the dangers of an adverse costs order if they allow their clients to raise spurious defences, as they too may be held liable for a proportion of any adverse costs order, which they will have to pay themselves - in addition to any order made against their clients. ${ }^{[1]]}$

\section{Conclusions}

Doctors should exercise extreme caution when relying solely on electronic communications to remind patients about necessary appointments - particularly when there is no response from the patient. They should always request their staff to follow up with a phone call to ensure that electronic messages have been received.

Doctors should also refrain from raising spurious defences that not only damage their reputation but may also result in the court imposing sanctions on them.

If a court is satisfied that a doctor has acted unethically and unprofessionally, the court may refer the court record to the HPCSA for disciplinary action. A doctor who lies to the court may be criminally prosecuted for perjury. 
Whenever doctors face allegations of medical malpractice or professional negligence that may have serious consequences, they should always contact their professional indemnity company to arrange a lawyer, or engage the services of a lawyer for themselves.

Declaration. None.

Acknowledgements. None.

Author contributions. Sole author.

Funding. National Research Foundation.

Conflicts of interest. None.

Medical Brief. Pretoria GP 100\% liable after failed SMS warning of deadly diagnosis. 13 February 2019 https://www.medicalbrief.co.za/archives/Pretoria-gp-100-liable-failed-sms-warning-deadly-diagnosis (accessed 15 April 2019).
2. Carstens P, Pearmain D. Foundational Principles of South African Law. Durban: LexisNexis, 2007:697-700. 3. Health Professions Council of South Africa. Health Professions Act 56 of 1974. Ethical rules of coalth Professions Council of South Africa. Health Professions Act 56 of 1974. Ethical rules of
conduct for practitioners registered under the Health Professions Act, 1974; Government Gazette No. conduct for practitioners registered under the Health Professions Act, 1974; Government Gazette No.
29079:R717. Pretoria: Government Printer, 2006 . 29079:R717. Pretoria: Government Printer, 2006.

4. Beauchamp TL, Childress JF. Principles of Biomedical Ethics. 3rd ed. Oxford: Oxford University Press 1994:67-113, 120-184, 194-249, 256-302.

5. Cf. R v Du Toit [1950] 2 All SA 518 (A).

6. Michael v Linksfield Park Clinic (Pty) Ltd 20013 SA 1188 (SCA)

7. NM Obo v MEC for Health, Eastern Cape Province Case No. 2035/2014; www.saflii.org/za/cases ZAECMHC/2018/27.pdf (accessed 19 April 2019).

8. Health Professions Council of South Africa. Rule 27A(e) of the Health Professions Council of South Africa. Guidance for Good Practice in Health Professions: Ethical and Professional Rules of the Health Professions Council of South Africa Booklet 2. Pretoria: HPCSA, 2016.

9. Van Wyk v Lewis $1924 \mathrm{AD} 438$.

10. Cf. Rule 3.2 of the General Council of the Bar of South Africa. Uniform Rules of Professional Ethics. Johannesburg: General Council of the Bar of South Africa, 2012.

11. Cf. Lushaba v MEC for Health, Gauteng 2015 (3) SA 616 (GJ) - overruled on a technicality in MEC for Health, Gauteng v Lushaba 2017 (1) SA 106 (CC).

Accepted 1 July 2019. 